\title{
Em busca do estado de conhecimento em Educação e Psicanálise
}

En busca del estado de conocimiento en Educación y Psicoanálisis

In search of the state of knowledge in Education and Psychoanalysis

Mariana Yuki Kamada

Escola Estadual Prof. Dr. Camilo Marques Paula - São Paulo-Brasil

Lilian Cristine Ribeiro Nascimento

Universidade Pública de Campinas - São Paulo - Brasil

\section{RESUMO}

O diálogo entre educação e psicanálise vem produzindo diversos estudos. Este artigo almeja ser um "estado do conhecimento" construído a partir da busca das palavras "educação e psicanálise" em dissertações e teses dos bancos de dados da Capes, restrito aos anos de 2011 e 2012, mas com alcance nacional; e das três universidades estaduais paulistas: USP, Unicamp e Unesp, até o ano de 2015. Foram analisados 163 resumos, classificados em relação à área de concentração, temática e autores citados. Os resultados demonstraram que as universidades públicas dominam os estudos pesquisados, e que a maior concentração de pesquisas ocorre na região sudeste do país. Freud e Lacan são os autores mais citados, seguidos por Winnicott. Os pesquisadores privilegiam o enfoque sobre ensino e aprendizagem, sendo a temática família a menos pesquisada.

Palavras-chave: Estado do conhecimento. Educação e psicanálise. Dissertações e teses.

\section{RESUMEN}

El diálogo entre educación y estudio viene produciendo diversos estudios. Este artículo almeja ser un "estado del conocimiento" construido a partir de la búsqueda de las palabras "educación y psicoanálisis" en disertaciones y tesis de los bancos de datos de Capes, restringido a los años 2011 y 2012, pero con alcance nacional; Y de las tres universidades estatales paulistas: USP, Unicamp y Unesp, hasta el año 2015. Se analizaron 163 resúmenes, clasificados en área de concentración, temática y autores citados. Los resultados demostraron que las universidades públicas dominan los estudios investigados, y que una mayor concentración de investigaciones ocurre en la región sudeste del país. Freud y Lacan son los autores más citados, seguidos por Winnicott. Los investigadores privilegian el enfoque sobre enseñanza y aprendizaje, siendo una familia temática investigada.

Palabras clave: Estado del conocimiento. Educación y psicoanálisis. Disertaciones y tesis. 


\begin{abstract}
The dialog between education and psychoanalysis has been fueling many studies. This article craves to be a "state of knowledge" built from the search of the words education and psychoanalysis in dissertations and thesis in the Capes database, which is restricted to the years of 2011 and 2012, but with national reach; and in the databases of the three state universities of São Paulo: USP, Unicamp and Unesp, up to the year of 2015. A total of 163 abstracts were analyzed and classified regarding their concentration area, subject and cited authors. The results demonstrated that the public universities dominate the studies in the researched fields, and that the largest concentrations of researches are in the Southeast region of Brazil. Freud and Lacan are the most cited authors, followed by Winnicott. The researchers favor the teaching and learning subjects, with family being the least researched theme.
\end{abstract}

Keywords: State of knowledge. Education and psychoanalysis. Dissertations and thesis.

\section{Introdução}

Em 1972, Victor Giudice escreveu a irônica história de João, um trabalhador que ao longo dos anos recebe diminuições de salário, rebaixamentos e, finalmente, ao completar 40 anos de bom trabalho, tem seu salário eliminado. Em resposta a isto:

João afastou-se. O lábio murcho se estendeu. A pele enrijeceu, ficou lisa. A estatura regrediu. A cabeça se fundiu ao corpo. As formas desumanizaram-se, planas, compactas. Nos lados, havia duas arestas. Tornou-se cinzento. João transformou-se num arquivo de metal (Giudice, 1972, p.4).

Para além da crítica à opressão trabalhista que permanece como discussão atual e que "coisifica" o sujeito, este conto também chama a atenção pela transformação do personagem principal em um arquivo como sinônimo de seu fim, sua morte. Os arquivos sempre exerceram fascínio, e inclusive houve a mudança de "arquivo morto" em arquivo em desuso.

Derrida (2001) faz um arquivo da própria palavra: Arkhe em sua origem grega corresponderia a começo e comando. Desta forma, é possível delimitar um princípio físico, histórico ou ontológico, local de início, e um princípio da lei, nomológico, no qual os homens e os deuses comandam. O arkhềon grego era inicialmente uma casa, um domicílio dos magistrados superiores. Os documentos oficiais eram ali guardados e seus ocupantes chamados de arcontes. Eles são os primeiros guardiões, hermenêuticos, e os que possuíam o poder de interpretar os arquivos. Afinal é o poder arcôntico que concentra as funções de unificação, identificação, classificação e de consignação, não apenas no sentido de reservar, mas de reunir. $\mathrm{O}$ conceito de arquivo remete-se primordialmente à memória.

Este artigo almeja ser um "estado do conhecimento" circunscrito às palavras educação e psicanálise. A pesquisa utilizou as dissertações e teses (mestrado e doutorado) sobre a temática, a partir dos arquivos da Coordenação de Aperfeiçoamento de Pessoal de Nível Superior (Capes), e das três universidades estaduais paulistas: Universidade de São Paulo (USP), Universidade Estadual de Campinas (Unicamp) e Universidade Estadual Paulista "Júlio de Mesquita Filho" (Unesp).

Vale lembrar, não somente o inconsciente proposto pela psicanálise abalou as ciências humanas, como também a internet modificou as relações sociais de um jeito que seria inimaginável para Freud e seus contemporâneos. Esta pesquisa é uma 
possibilidade facilitada pelo advento da web, porque há de tudo na rede.Portanto, as informações estão também, basta procurá-las, catalogá-las... quase tudo é arquivado.

Kupfer et al. (2010) indicam, após o levantamento da literatura, que existem várias maneiras de encarar o encontro entre os saberes da educação e da psicanálise. Muitas vezes se configuram como uma relação de exterioridade. Assim, são apresentados, de forma paralela, a psicanálise como ditadora de regras e prescrições; e a educação na função de esclarecer os processos do campo pedagógico. No entanto, existe outra forma de estabelecer a conexão que seria mais iluminadora: ampliar o ato educativo de modo a considerar também a dimensão libidinal, cuja implicação é na construção de um sujeito de desejo. Assim, o campo educativo transforma-se, e pode ser entendido como Educação para o sujeito.

Esta reflexão é bastante válida já que Freud afirma que em termos de aplicação, a educação é o que despertou o maior interesse, e também a esperança de diversos capazes colaboradores (Freud, 2006[1925]). Na questão da esperança, há um pouco de ironia, afinal é preciso ultrapassar a categoria do impossível. Segundo Kupfer (2000), Freud faz parte da coleção de pensadores da educação por dois motivos. Por um lado, um peculiar modo de produzir teoria, pensar e desejar, como também a forma com que suas ideias se alastraram, e desta transmissão poder obter-se algo de pedagogia, como a questão dos discípulos, brigas teóricas, etc. E, por outro lado, abriu espaço para reflexão sobre o que é ensinar, o que é aprender.

Muitos pesquisadores já percorreram este caminho, seja para refutar, corroborar, ou para inovar a partir do pensamento freudiano, e muitas destas pesquisas são, ainda hoje, objeto de estudos nas universidades brasileiras.

\section{Método}

O "estado do conhecimento" é uma pesquisa que é considerada de caráter bibliográfico e quantitativo, e encontra sua importância ao organizar e analisar as produções acadêmicas (artigos, dissertações, entre outros) de uma determinada área científica, mas apenas em um formato específico, por exemplo, dissertações, em um período de tempo (Ferreira, 2002). Diferenciase do "estado da arte", que são estudos que abrangem toda área e conhecimento, nos diferentes aspectos de produção acadêmica (Romanowski \& Ens, 2006).

A justificativa para este tipo de levantamento bibliográfico encontra-se na construção de uma visão geral da produção e de sua ordenação por área e temas trabalhados. Ademais, é identificar possíveis lacunas nas pesquisas (Romanowski \& Ens, 2006).

"Educação" e "Psicanálise" são as palavras-chave para a presente pesquisa, seja na busca no campo das palavras-chave ou no campo assunto. Buscou-se a presença das duas palavras no sistema de busca de dissertações e teses da Capes e de três universidades públicas paulistas: USP, Unesp e Unicamp.

Dois esclarecimentos principais e gerais são necessários. Primeiro, o uso de mais de um banco de dados, que inclusive se cruzam, tem como objetivo abarcar um maior período de tempo, uma vez que o banco de dados da Capes em relação às dissertações e teses, apesar de ser nacional, no momento da pesquisa apresentava apenas os dados dos trabalhos defendidos em 2011-2012, período contemplado na pesquisa deste banco. Já os bancos de dados das universidades estaduais paulistas, apesar de trazerem resultados menores em termos de quantidade, têm o intuito de colher impressões sobre a produção referente ao assunto ao longo de alguns anos (1989-2015). Não é uma questão de comparar a quantidade de trabalhos produzidos (Capes e universidades paulistas), mas ter duas perspectivas diferentes, sem que mutuamente se excluam.

O segundo esclarecimento é que são diferentes bancos de dados, logo as opções de pesquisa também o são. Por exemplo, no 
catálogo da Unesp não há busca por palavraschave, mas por assunto. Existem peculiaridades que atravessam o pesquisar em cada arquivo. Neste catálogo por não disponibilizar a busca por palavras-chave, utilizou-se o campo assunto para a pesquisa. Cabe lembrar, outras dissertações e teses poderiam tratar do assunto, mas não ter estas palavras-chaves.

Em específico o arquivo da Capes, ou o banco de teses, como intitulado pela agência, é bastante simples de ser utilizado, no entanto seu intuito não é a disponibilização do texto na íntegra, apenas a divulgação das produções. A busca básica, com as palavras-chave "educação e psicanálise", encontrou 166 registros no total que abrangiam os anos de 2011e 2012, dos quais foram excluídos 67 trabalhos. Houve dois critérios de exclusão de análise: quando havia apenas um dos termos da pesquisa no resumo; e quando, mesmo presentes, não estavam relacionados ao trabalho como um todo, apenas como uma citação genérica.

Outro ponto importante é a necessidade do pesquisador conhecer o tema a ser inventariado, porque este saber prévio, ou seja a familiaridade, permite a tomada de certas decisões. Uma dissertação, intitulada Orientadores sociais voluntários no programa liberdade assistida: paradoxos da experiência de Belo Horizonte, em específico, suscitou questionamentos porque a partir da busca por "educação e psicanálise" o estudo apareceu, porém, essas duas palavras não são encontradas no resumo da pesquisa. No entanto, é possível inferir a interface buscada, já que algumas palavras emblemáticas são utilizadas, como, por exemplo, "significante", acompanhado de uma referência a um autor de base psicanalítica. Assim, um olhar específico permitiu deduzir o referencial teórico adotado e a inclusão do trabalho neste levantamento.

$\mathrm{O}$ enquadro da pesquisa envolveu as produções por estado, o período delimitado, as áreas do conhecimento abarcadas, a temática apresentada, e autores citados no resumo. O trabalho tem dois momentos: o levantamento realizado no banco de dados da Capes e depois nas estaduais paulistas. Ambos ocorreram em janeiro de 2016.

\section{Resultados e Discussão}

As universidades públicas dominam as produções com 74 estudos, enquanto as instituições particulares produziram 25 trabalhos. A USP detém o maior número (18), tanto de mestrados (12), quanto de doutorados (6) nesta temática, possuindo o dobro do número apresentado pela universidade em segundo lugar, a Universidade Federal do Rio Grande do Sul (UFRGS).

É interessante notar o número de universidades que possuem apenas dois ou um estudo nesse tema. São dez e treze, respectivamente. É um indicativo importante de que o tema "educação e psicanálise" está no mínimo presente em diferentes instituições de ensino.

O quadro 1, a seguir, indica o número de produções por estados brasileiros. 
Quadro 1 - Produções por estados

\begin{tabular}{lc}
\hline Estados & $\mathbf{N}^{\mathbf{0}}$ de trabalhos \\
\hline São Paulo & 35 \\
Rio de Janeiro & 16 \\
Rio Grande do Sul & 14 \\
Goiás & 13 \\
Minas Gerais & 7 \\
Paraná & 6 \\
Bahia & 3 \\
Alagoas, Ceará, Paraíba, & 1 cada \\
Pernambuco, Rio Grande do & \\
Norte & \\
\hline Fonte: elaborada pelas autoras.
\end{tabular}

São Paulo é o Estado de maior produtividade, o que é reflexo do próprio viés de partida do Estado, em termos de história, e investimentos para a pesquisa. Em relação às regiões, é a Sudeste que apresenta a maior concentração de produções, seguida por Sul e Nordeste. O Centro-Oeste é representado pelo estado de Goiás, com a Universidade de Brasília com o maior número de produções desta região. O Rio Grande do Sul é o estado que se destaca na região Sul do país. Já o Norte, não possui representatividade no estudo do tema, a partir da perspectiva da presente pesquisa. Isto pode ser compreendido a partir da própria história da criação das universidades no Brasil e o papel da pósgraduação (Balbachevsky, 2005). O mapa abaixo é um recurso didático para melhor visualizar as produções por Estado.

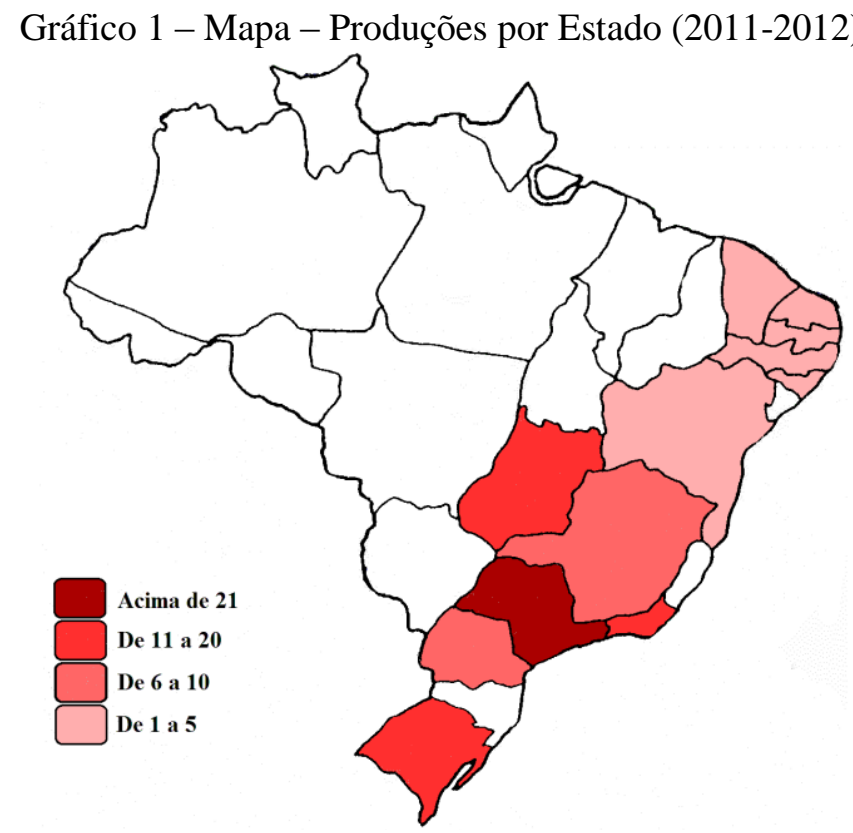

Fonte: elaborado pelas autoras.

Com base no mapa, nota-se que os grandes polos de investigação estão nos grandes centros educativos. No entanto, fica em aberto a pergunta: para além da questão histórica de desenvolvimento dos estados, existe algo que movimenta o diálogo entre educação e psicanálise em alguns lugares e em outros não? É preciso refletir sobre a questão da transmissão da psicanálise. O próprio saber 
psicanalítico extrapola os muros das universidades, como quando está na clínica.

O próximo ponto refere-se a um comparativo entre as universidades públicas e particulares em relação à quantidade de produções apresentadas sobre a temática pesquisada.

Gráfico 2 - Mestrado e doutorado nas instituições públicas e particulares

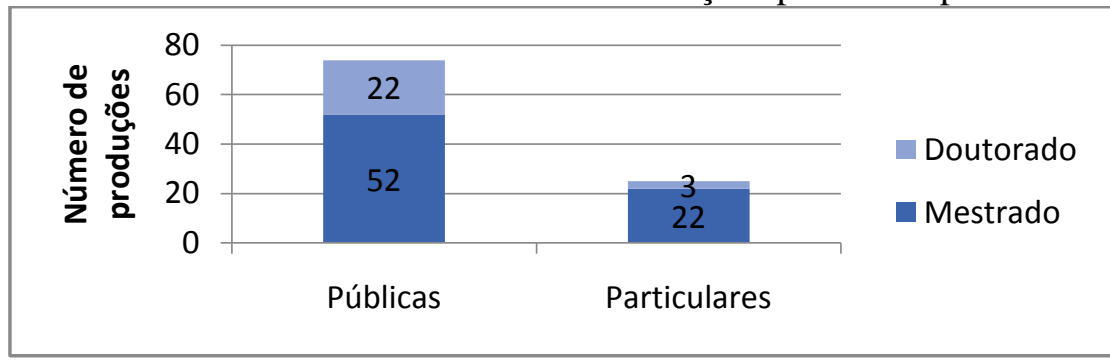

Fonte: elaborado pelas autoras.

Neste gráfico, é notável a discrepância entre instituições públicas e particulares, em relação ao mestrado e, principalmente, ao doutorado. Em números exatos, as instituições particulares produziram apenas três doutorados sobre o tema pesquisado, assim, sua maior concentração refere-se aos mestrados, com vinte e três trabalhos defendidos. Uma hipótese é que as próprias instituições particulares estejam mais voltadas ao mercado de trabalho, ainda que existam instituições como a Pontifícia Universidade Católica com vasta produção em pósgraduação, enquanto que, historicamente, as instituições públicas estão ligadas à produção de pesquisas e de trabalhos de viés acadêmico. Também a proporção de quase um para três, sinaliza, possivelmente, que a produção comparativa no geral seja desta mesma forma, mesmo em outros campos do conhecimento.

A seguir, uma discussão sobre as áreas do conhecimento às quais as pesquisas estão vinculadas. A área com a maior concentração de trabalhos é a Educação. É claro, ela é uma das palavras chaves da pesquisa. Porém, é interessante perceber como esta área se divide em outras mais específicas como o ensino nas ciências. E ainda, que ela pode estar relacionada a outros temas bastante amplos como cultura, comunicação e contemporaneidade. Também aparece relacionada ao tema saúde, que, por muitas vezes, é esquecido.

A segunda grande área é a da Psicologia/Psicanálise com $27 \%$ dos trabalhos, demonstrando sempre a importância destes saberes em diálogo com a educação. A psicologia,em suas diversas vertentes, possui diferentes objetos de estudo, porém é bastante relevante seu interesse na educação e em formas de contribuição na construção de um saber conjunto.

Em terceiro estão os trabalhos relacionados à área da Linguagem com 5\%, o que é bastante esperado diante das questões suscitadas pela psicanálise. E, por último, diferentes áreas agrupadas com apenas $4 \%$ das produções. Talvez esta seja uma lacuna importante nos trabalhos. Um maior diálogo com áreas e disciplinas bastante diferentes pode contribuir para a construção sempre constante do que é o saber da psicanálise em interface com a educação.

Abaixo, a tabela 1 demonstra as áreas do conhecimento. 
Tabela 1 - Mestrados e doutorados por área do conhecimento (2011-2012)

\begin{tabular}{|c|c|c|c|}
\hline \multirow{2}{*}{ Área do conhecimento } & \multicolumn{2}{|c|}{ Número de pesquisas } & \multirow{2}{*}{$\%$} \\
\hline & $\mathrm{ME}$ & $\mathrm{DO}$ & \\
\hline \multicolumn{4}{|l|}{ Educação } \\
\hline $\begin{array}{l}\text { e contemporaneidade / cultura e comunicação / e saúde na infância } \\
\text { e adolescência / escolar / nas ciências /ensino de ciências e } \\
\text { educação. }\end{array}$ & 43 & 19 & $63 \%$ \\
\hline Psicologia/ Psicanálise & & & \\
\hline $\begin{array}{l}\text { clínica / clínica e cultura / escolar e do desenvolvimento humano / } \\
\text { social e institucional/saúde e sociedade / Terapia Psicanalítica. }\end{array}$ & 25 & 3 & $28 \%$ \\
\hline \multicolumn{4}{|l|}{ Linguagem } \\
\hline $\begin{array}{l}\text { Estudos linguísticos e literários em inglês / letras/ linguística } \\
\text { aplicada. }\end{array}$ & 4 & 1 & $5 \%$ \\
\hline \multicolumn{4}{|l|}{ Outras } \\
\hline $\begin{array}{l}\text { Ciências do exercício e do esporte / Ciências sociais/ História das } \\
\text { ciências / Meios e processos audiovisuais / saúde coletiva. }\end{array}$ & 2 & 2 & $4 \%$ \\
\hline Total & 74 & 25 & $100 \%$ \\
\hline
\end{tabular}

Fonte: elaborada pelas autoras.

Após os apontamentos acima sobre as áreas, é possível fazer uma reflexão sobre as temáticas pesquisadas. Sem dúvida, é uma grande aposta estabelecer grupos de temas e apontar onde cada estudo se encontra a partir da leitura de um resumo. Um mesmo estudo pode tratar de vários temas indiretamente, e nem sempre os resumos eram claros a este respeito. As categorias são: ensino e aprendizagem; o professor e suas questões; educação especial; o sujeito e sua especificidade; relação professor e aluno; contribuições da psicanálise; e família. A seguir, a caracterização de cada uma.

1. Ensino e Aprendizagem: trabalhos sobre os mecanismos que envolvem o ensino e a aprendizagem; bastante recorrentes também as pesquisas que perpassam pela questão da aquisição da escrita; o uso de dispositivos tidos como não usuais dentro da escola, como o uso de fábulas, ou o lúdico; e questões envoltas ao desejo de aprender, ou seu oposto, a falta de interesse. Esta categoria centra-se principalmente no aluno/criança/adolescente.

2. O professor e suas questões: pesquisas que abordam os sentimentos como angústia e medo, ou seja, a subjetividade do professor, escolha profissional, ou prática atual; também são encontrados aqui os estudos sobre formação profissional e continuada em cursos, ou intervenção de psicólogos presentes na escola; e pesquisas no entorno da gestão escolar, porque, de fato, usualmente são professores que ocupam estes cargos.

3. Educação especial: sujeitos acometidos por transtornos globais de desenvolvimento; estudos acerca da psicose; Transtorno de Déficit de Atenção e Hiperatividade (TDHA); e deficiências, educação especial e inclusão.

4. O sujeito e sua especificidade: estudos que envolvem algo de específico sobre determinada fase de desenvolvimento, ou em alguma situação atípica, como tratamento oncológico; criança "problema"; estudos sobre violência sexual; e adolescentes em acolhimento institucional como medida sócio educativa.

5. Relação professor-aluno: pesquisas que estudam a relação entre professor e aluno em diferentes níveis, desde o ensino infantil, até o universitário; conceitos psicanalíticos de transferência e contratransferência; e trabalhos que envolvem as duas categorias: Ensino e aprendizagem e $\underline{\mathrm{O}}$ professor e suas questões, mas sob a 
perspectiva específica da relação entre os dois sujeitos da educação.

6. Contribuições da Psicanálise: pesquisas teóricas que tratam da história da psicanálise na educação, assim como trabalhos sobre psicanalistas e suas contribuições; (im)possibilidades da psicanálise aplicada; e mal-estar presente no ato de educar.

Segue tabela síntese em ordem decrescente com os dados obtidos da análise.

\begin{tabular}{lc}
\multicolumn{2}{c}{ Quadro 2- Síntese (dissertações e teses por tema) } \\
\hline Categorias - Temas & N $^{\mathbf{o}}$ de trabalhos \\
\hline Ensino e aprendizagem & 22 \\
O professor e suas questões & 17 \\
Educação especial & 15 \\
O sujeito e sua especificidade & 14 \\
Relação professor-aluno & 13 \\
Contribuições da psicanálise & 10 \\
Família & 8 \\
\hline
\end{tabular}

Fonte: elaborada pelas autoras.

Ensino e aprendizagem é majoritariamente o maior objeto de estudo dos pesquisadores. É realmente o que os move, a busca por novas metodologias, ou para apontar críticas ao que tradicionalmente é feito. (Ex.: O reforço escolar na educação integral: uma leitura a partir da psicanálise; Desejo $e$ Aprendizagem). Adiciona-se a categoria $\underline{\mathrm{O}}$ professor e suas questões e está posto o outro lado da moeda, mas com o professor no centro. Chamam a atenção os sentimentos negativos que são atribuídos a eles, medo, mal-estar, mesmo que seja em um viés de questionamento. Um dos títulos de pesquisa é bastante significativo: $O$ (des)encanto do professor: angústia manifesta na contemporaneidade. Ademais, na intersecção destes dois campos está a Relação professor aluno, com numerosos estudos (Ex: Psicanálise e Educação à distância; A relação professor-aluno e seus impasses).

A partir de uma perspectiva histórica do estudo da interação entre professor e aluno, percebe-se que é "esmagadoramente majoritária pelas tentativas de definir e medir a eficácia docente, fosse com fins de pesquisa,
7. Família: estudos com os familiares do aluno em diálogo com a escola. Papel do pai/mãe no desenvolvimento educacional da criança; função paterna, materna; escuta dos pais; e experiência de ser mãe. ou para incidir na formação dos professores" (Coll \& Solé, 1996, p.282). Portanto, é preciso trazer outras perspectivas ao estudo educacional, sem desconsiderar, entretanto, o papel do professor.

O tema Educação Especial é a terceira categoria. Os trabalhos abarcam diferentes deficiências. E são importantes as discussões a respeito, diante das mudanças de paradigmas na educação em relação ao papel do Estado no oferecimento da inclusão escolar (Ex.: Sua majestade o autista: fascínio, intolerância e exclusão no mundo contemporâneo; Alunos com transtornos globais de desenvolvimento: da categoria psiquiátrica à particularidade de cada caso no processo de inclusão escolar).

A quarta categoria, $\underline{O}$ sujeito e sua especificidade, tem estudos importantes para situações que exigem uma perspectiva específica diante da situação momentânea do sujeito, como no caso de adolescentes em medidas sócio educativas (Ex.: Sexualidade e gênero de adolescentes em conflito com a lei; Laço da laje:jovens produtores de cultura). 
As contribuições da psicanálise configuram-se como uma temática importante. Em muitos casos são de cunho teórico e histórico, mas delimitam os alcances do encontro, as possibilidades e impossibilidades deste profícuo diálogo entre educação e psicanálise (Ex: De que serve a Psicanálise à educação escolar; Psicanálise e Educação: da sustentação do enigma à construção do saber).

Existe uma diferença bastante preponderante ao considerar a primeira categoria e a última, Família, com o menor número de trabalhos (Ex: Função paterna $e$ seus desdobramentos junto à educação; Escuta grupal de pais de crianças com problemas de desenvolvimento: uma proposta metodológica baseada na psicanálise). É interessante notar que uma das principais queixas dos professores para os problemas dentro da escola é o que se rotula como "família desestruturada", que é a diferente da nuclear burguesa composta por mãe, pai e filhos. O Art. $4^{\circ}$ do Estatuto da Criança e do Adolescente de 1990 informa:

Art. $4^{\circ}$ É dever da família, da comunidade, da sociedade em geral e do poder público assegurar, com absoluta prioridade, a efetivação dos direitos referentes à vida, à saúde, à alimentação, à educação, ao esporte, ao lazer, à profissionalização, à cultura, à dignidade, ao respeito, à liberdade e à convivência familiar e comunitária (BRASIL, 1990, s/p) [grifo nosso].

$\mathrm{O}$ artigo explicita que há uma responsabilidade compartilhada, se uma instituição falta, outra deve suprir. A questão é que o papel da família, no senso comum, é centrar-se no desenvolvimento psicológico e moral, ou seja, na formação da personalidade, enquanto que o desenvolvimento do conhecimento ficaria a cargo da escola (Vilela \& Archangelo, 2013).

Uma lacuna aqui mostra a necessidade de mais estudos em relação ao papel da família no desenvolvimento das crianças, no sentido educacional. Uma hipótese a ser averiguada é se não há interesse dos pesquisadores e/ou se os familiares relutam em participar de pesquisas empíricas por falta de tempo, por desinteresse, ou porque seriam convocados a refletir sobre as próprias práticas parentais e possíveis responsabilidades. O intuito aqui não é a culpabilização da família, conforme sinalizado por Patto (1992), mas uma compreensão da importância dela na vida do sujeito, sem entrar no mérito da configuração, se tradicional ou não. Por outro lado, é preciso reforçar o papel da escola na figura do Estado, como promotora de desenvolvimento, apesar e com a família.

Depois de passar pelas temáticas, é necessário iniciar as discussões sobre o referencial teórico utilizado nas pesquisas. Buscou-se delimitar a citação de autores no resumo. Presume-se que uma pesquisa em nível de pós-graduação abarque uma vasta pesquisa bibliográfica, portanto é muito significativo um autor/pesquisador ser citado no resumo. Com base no quadro 3 , a seguir, considerações sobre os autores citados serão feitas. 
Quadro 3 - Autores citados nos resumos

\begin{tabular}{lc}
\hline Autor(a) & No $^{\text {de citações }}$ \\
\hline Freud e Lacan em conjunto & 23 \\
Freud & 13 \\
Lacan & 10 \\
Winnicott & 6 \\
Foucault & 4 \\
Hermann / Lajonquière / Kupfer / & 3 \\
Orlandi / Piaget / Saussure & \\
Authier-Revuz / Bauman / Charlot / & 2 \\
Lemos / Kehl & \\
Outros & 53 \\
Nenhum autor é citado & 32 \\
\hline
\end{tabular}

Fonte: elaborada pelas autoras.

A primeira observação pertinente é que existem mais citações em conjunto de Freud e Lacan do que propriamente do pai da psicanálise individualmente, o que indica que a psicanálise brasileira em termos de educação enxerga o inconsciente por meio da lente da psicanálise francesa lacaniana.

Anna Freud, Donald Winnicott e Melanie Klein são psicanalistas clássicos que estudaram especificamente as crianças, a partir do atendimento clínico realizado com elas. Nenhum deles desenvolveu uma teoria específica da aprendizagem, porém, por meio desta pesquisa, notou-se a prevalência do inglês Winnicott na busca de transpor o conhecimento clínico ao contexto educacional. Michel Foucault, um filósofo francês também é citado.

Os pesquisadores brasileiros mais citados foram: Hermann, um médico psicanalista que desenvolveu a teoria dos campos e possui importantes estudos acerca do método psicanalítico; Lajonquière e Kupfer, acadêmicos da USP, e Orlandi, importante nome da Análise do Discurso brasileira. A Análise do Discurso possui filiação teórica na relação de três domínios disciplinares que são rupturas com o século XIX, a psicanálise, a linguística e o marxismo (Orlandi, 2001).
Prevaleceram as categorias em que aparecem diversos outros autores citados apenas uma vez, ou em que não havia citação de nenhum autor nos resumos, demonstrando que em certos trabalhos não há um referencial teórico dominante, por uma tentativa de conciliar muitos saberes e assim não se comprometer a uma vertente teórica específica. Ou por não haver interesse de expor o referencial para não restringir o alcance do trabalho, esquecendo que um dos objetivos do resumo é justamente enquadrar o estudo em uma tradição teórica.

Em síntese, a pesquisa no banco de teses da Capes estava delimitada pelas produções que ocorreram nos anos 2011-2012, no entanto mostrou-se bastante frutífera por expor áreas de conhecimento, temáticas e referenciais teóricos utilizados pelos pesquisadores brasileiros.

\section{As Estaduais Paulistas: USP, Unicamp e Unesp}

As três universidades estaduais paulistas, USP, Unicamp e Unesp, são importantes centros de ensino e pesquisa. $\mathrm{O}$ levantamento de produções em complemento ao que já foi apresentado tem o intuito de ampliar esta pesquisa. Cada universidade possui um mecanismo de busca diferente, que 
engloba diferentes necessidades de pesquisa. A seguir, mais detalhes relacionados aos mecanismos de busca de cada uma das universidades paulistas contempladas neste trabalho.

A USP apresentou o menor número de trabalhos, no entanto é importante ressaltar que a busca ocorreu, neste caso, a partir das palavras-chave, ou seja, os autores/pesquisadores necessariamente deveriam escolher as palavras educação e psicanálise em conjunto. Este foi o filtro delimitado por esta pesquisa. E, justamente por isso, nenhum trabalho foi excluído, porém, a título de informação, se houvesse a ampliação para a pesquisa destas palavras por meio do campo resumo, o número de entradas seria muito maior.

Tanto a Unicamp quanto a Unesp tiveram alguns trabalhos excluídos da análise, pelos mesmos motivos apresentados anteriormente em relação à Capes. Muitas vezes a palavra psicanálise aparece em comparativo com outras áreas do conhecimento.

O quadro 4 mostra os números levantados, sendo que o período não foi especificado, abarcando, portanto,todas as produções arquivadas até janeiro de 2016.

\begin{tabular}{lccc}
\multicolumn{4}{c}{ Quadro 4- Produções por universidades paulistas } \\
\hline & USP & Unicamp & Unesp \\
\hline $\mathrm{N}^{\circ}$ de registros & 16 & 27 & 32 \\
Excluídos & 0 & 5 & 6 \\
Total & 16 & 22 & 26 \\
\hline Fonte: elaborada pelas autoras. & &
\end{tabular}

Houve um trabalho que chamou atenção, intitulado Formação Inicial de professores: problematizações, reatualizações de discursos e produção de narrativas, uma tese de doutorado realizado na Unicamp no ano de 2011, portanto, era para constar também no banco de dados da Capes e, curiosamente, não foi localizado pelo mecanismo de busca anterior. As palavraschaves eram diferentes. No arquivo da Unicamp eram: Formação inicial do professor, Docência, Estagiários-Narrativas pessoais, Psicanálise e educação; já no banco de dados da Capes: formação inicial professores, relação com docência, analogia.
Uma lição bastante importante pode ser tirada deste caso específico: arquivos provavelmente escondem mais do que revelam. O trabalho minucioso percebeu esta mudança de palavras-chaves, no entanto diversos outros trabalhos relacionados ao tema podem estar escondidos nos arquivos trabalhados. Isto faz com que se possa questionar o alcance de um trabalho de "Estado do Conhecimento". Por outro lado, faz ressaltar a importância do viés psicanalítico, isto é, escancara uma falta que revela a impossibilidade de catalogar ou arquivar tudo.

Segue mais um gráfico a ser analisado com as produções universidades paulistas: 
Gráfico 1 - Produção de mestrados e doutorados por ano (1989-2015)

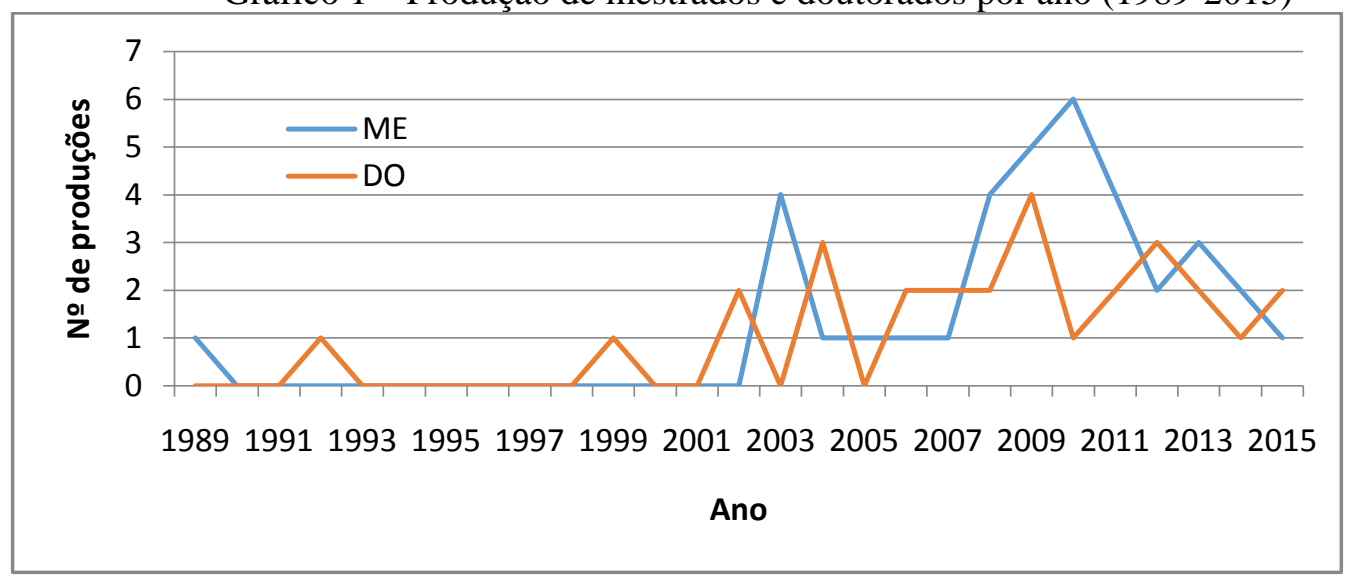

Fonte: elaborado pelas autoras.

O gráfico 3 indica a evolução em relação à quantidade encontrada de produções de mestrados e doutorados. Por meio do gráfico, é possível afirmar que até o ano 2001 as pesquisas neste campo foram poucas e esporádicas, totalizando apenas três. A partir de 2002, a produção que aparece em torno das palavras-chave "educação e psicanálise" tornase mais consistente, período no qual o número de teses de doutorado se mantém relativamente constante. Já as dissertações tiveram um aumento significativo entre os anos de 2008 e 2012.

A tabela 2 é uma ilustração das áreas de conhecimento dos trabalhos analisados.

Tabela 2 - Mestrados e doutorados por área de conhecimento - estaduais paulistas (1989-2015)

\begin{tabular}{|c|c|c|c|}
\hline \multirow[b]{2}{*}{ Área de conhecimento } & \multicolumn{2}{|c|}{ Número de pesquisas } & \multirow[b]{2}{*}{$\%$} \\
\hline & ME & DO & \\
\hline $\begin{array}{l}\text { Educação } \\
\text { escolar / matemática / física / Ensino de ciências }\end{array}$ & 27 & 21 & $75 \%$ \\
\hline$\frac{\text { Psicologia }}{\text { clínica / escolar e do desenvolvimento humano / social }}$ & 5 & 4 & $14 \%$ \\
\hline Outras & & & \\
\hline $\begin{array}{l}\text { Serviço social / Saúde mental / Linguística / Música / Artes / } \\
\text { Ciências da motricidade }\end{array}$ & 4 & 3 & $11 \%$ \\
\hline TOTAL & 36 & 28 & $100 \%$ \\
\hline
\end{tabular}

Fonte: elaborada pelas autoras.

Com relação às áreas de conhecimento vinculadas às titulações, a educação é a que se destaca, com $75 \%$ das dissertações e teses publicizadas. A especificidade também é notável, tendo como exemplo mestrado em educação matemática, ou seja, é mais um campo que entra nas discussões neste texto. E, em segundo lugar, a área da psicologia, o que identicamente era esperado. No entanto, é importante ressaltar a existência de outros campos do saber, como, por exemplo, a música, o que reafirma a sinalização para as variedades do alcance da psicanálise para além da educação.

Apesar dos doutorados estarem presentes em um número menor, o que já é esperado pelo grau de especialização e pelos 
requerimentos inerentes à pesquisa deste tipo, a quantidade é bem próxima da dos mestrados. utilizadas para categorizar os estudos encontrados no banco de dados da Capes.

O quadro 5 refere-se às temáticas. Para compreensão global, são as mesmas já

Quadro 5 - Universidades estaduais e as temáticas (1989-2015)

\begin{tabular}{ccccc} 
Categorias - Temas & \multicolumn{5}{c}{$\mathrm{N}^{\mathbf{0}}$ de trabalhos } \\
\cline { 2 - 5 } & USP & Unesp & Unicamp & Total \\
\hline Ensino e aprendizagem & 4 & 7 & 5 & 16 \\
O professor e suas questões & 5 & 5 & 9 & 19 \\
Educação especial & 2 & 4 & 1 & 7 \\
O sujeito e sua especificidade & 0 & 5 & 2 & 3 \\
Relação professor aluno & 0 & 1 & 2 & 11 \\
Contribuições da psicanálise & 5 & 3 & 3 & 1 \\
Família & 0 & 1 & 0 & 7 \\
\hline
\end{tabular}

Fonte: elaborada pelas autoras.

$\mathrm{O}$ quadro 5 apresenta a temática $\underline{\mathrm{O}}$ professor e suas questões como a principal área de pesquisa nas universidades estaduais paulistas; em seguida, Ensino e aprendizagem; e, em um número bastante relevante, as Contribuições da psicanálise. Educação $\underline{\text { especial e } \underline{O} \text { sujeito e sua especificidade }}$ apresentam sete trabalhos cada.

As pesquisas que versam sobre a Relação professor aluno, com apenas três trabalhos, e o tema Família, ou seja, estudos sobre a família, papel do pai, da mãe, que é tratado em apenas uma dissertação da Unesp, são numericamente ínfimas.

Em relação ao referencial teórico, Freud foi o autor mais citado. Ainda que, especificamente na Unicamp, a influência lacaniana seja bastante marcante. Winnicott é o pesquisador de crianças mais lembrado. $\mathrm{O}$ psicanalista francês Kaës está presente na USP e na Unicamp. E o filósofo alemão Adorno, único da lista que não é psicanalista, é citado em estudos da USP e da Unesp. O único brasileiro que é citado mais de duas vezes nos resumos analisados é Herrmann, por sua influência na Unesp. Diversos outros autores também são citados, o que é muito válido, ao contrário, os trabalhos poderiam carecer de diversidade teórica, própria a uma Universidade.

\section{Um balanço das análises}

A elaboração deste estudo encontrou algumas dificuldades ao fazer o levantamento dos arquivos da Capes e das estaduais paulistas, seja na escolha, no uso dos mecanismos de busca, da necessidade de consulta dos sites por várias vezes. No entanto, o maior desafio encontrou-se na análise dos resumos dos trabalhos, e não pelo que está descrito em linhas gerais, mas pelo contrário, pela falta, pelas lacunas deixadas, mesmo existindo uma ideia de padronização metodológica na confecção dos resumos, na presença de objetivos, referencial teórico, procedimentos, entre outros.

A leitura dos resumos pode deixar a sensação de equívoco no sentido da 
classificação de um trabalho a partir de um enquadre específico. A questão é que o resumo oferece uma das possibilidades de visão sobre aquela dissertação ou tese (Ferreira, 2002).

Teixeira (2011), em dissertação de mestrado, faz um "Estado da Arte" em busca do conceito de criatividade na relação com o aprender, dentro do referencial psicanalítico. Ao analisar resumos a partir dos bancos de dados da Capes, escreve que não há uma forma padronizada na apresentação dos resumos. Inclusive, muitos pesquisadores não explicitam o tipo de estudo e o procedimento de coleta de dados.

Atualmente, em muitas ocasiões a relação das pessoas com o tempo é mediada por um valor mercantil. Pode-se imaginar que os pesquisadores querem um resumo que economize o tempo, no sentido de conter as informações tidas como úteis e concretas nos termos metodológicos para leitura ou não daquele trabalho. Na verdade, o ponto mais importante não deveria ser a padronização, mas a função de despertar no leitor o desejo de ler o texto na íntegra, em uma espécie de sedução pelo conhecimento, e, para isso, cada escritor/autor que é pesquisador deve encontrar um caminho singular de escrita, a despeito das dificuldades deixadas para os que querem posteriormente catalogar as informações contidas.

Mesmo diante dessas dificuldades, muito se pode apreender das análises feitas. As produções das universidades estaduais paulistas é que garantem a São Paulo o status de referência acerca da temática "educação e psicanálise".

Em comparativo ao que foi encontrado como temáticas no banco de dados da Capes, elas foram muito mais equilibradas em termos de variedade das pesquisas. O que chamou atenção é que a produção nacional foi majoritariamente em termos de Ensino e aprendizagem, ou seja, uma centralização na relação professor-aluno. Enquanto que nas estaduais paulistas, a temática dominante foi o Professor e suas questões, em especial na
Unicamp. Uma hipótese que poderia ser investigada é o bombardeio nas mídias paulistas sobre o papel do professor, e claro, suas falhas, no sentido do que o senso comum compreende como o ser professor.

Sobre o referencial teórico, a análise indica Freud, Lacan e Winnicott como os autores de maior influência na produção psicanalítica educacional dentro dos parâmetros pesquisados, ainda que muitos outros autores sejam citados.

Outra pergunta que merece destaque: os professores estão se transformando em arquivos de metal como na história de João que abre este artigo, que depois de anos de trabalho, tem este fim? São tantos manuais, tantos conselhos de como ser professor, e tantas exigência burocráticas, tantos papéis para se preencher que se descaracteriza sua função como mediador das aquisições culturais da humanidade, e, neste sentido, são todos transformados em coisas obsoletas como um arquivo de metal. Por outro lado, há no cotidiano escolar pequenas insurreições, que se configuram como práticas inovadoras sem necessariamente serem tecnológicas, ou até mesmo sendo. No lugar da missão pedagógica, salvadora do mundo, que a permanência seja dos professores que inspiram seus alunos, porque estes sempre existiram. O papel da psicanálise aqui é abrir um espaço de escuta destas histórias, principalmente quando elas não são inspiradoras, mas tristes, angustiantes ou indomáveis e legitimar estes sentidos. Permitir o falar do que se esconde é a maior força do saber psicanalítico. E esse alcance não se restringe ao professor

Uma última reflexão sobre esta pesquisa: segundo Roudinesco (2006), no historiador e nas pessoas apaixonadas pelo arquivo há uma espécie de culto narcísico do arquivo quando transformado em saber absoluto, espelho de si e, nesse sentido, a história como criação não existiria. E, por outro lado, se nada é arquivado, ou está simplesmente destruído, a história tende para fantasia, simplesmente uma "soberania delirante do eu", um dogma. 
Já o historiador Peter Gay (1989) afirma que a velha divisão entre arte e ciência é insustentável para a história, pois ela é ambas. A arte do historiador constitui sua ciência e é possível encontrar uma variedade de modos de se atingir verdades históricas. E ainda, demônios pessoais ditam uma perspectiva extremamente limitante sobre o passado, no entanto, este mesmo estilo pode

\section{Referências}

Balbachevsky, E. (2005). A pós-graduação no Brasil: novos desafios para uma política bem sucedida. In: C.Brock, \& S.

Schwartzman (Orgs). Os desafios da educação no Brasil (pp. 285-314). Rio de Janeiro: Nova Fronteira.

Derrida, J. (2001). Mal de Arquivo - Uma impressão freudiana. Rio de Janeiro: Relume Dumará.

Ferreira, N. S. de A (2002). As pesquisas denominadas "estado da arte". Educação \& Sociedade (79), 257-272.

Freud, S. (2006[1925]). Prefácio à Juventude Desorientada de Aichhorn [1925]. Edição Standard.

Brasil. Lei no 8.069, de 13 de julho de 1990 (1990). Dispõe sobre o Estatuto da Criança e do Adolescente e dá outras providências. Brasília, DF. Recuperado em 27 de março de 2017, de www.planalto.gov.br/ccivil_03/LEIS/L806 9.htm

Brasileira das Obras Psicológicas Completas de Sigmund Freud -Vol.XIX. Rio de Janeiro: Imago.

Gay, P. (1989). Freud para historiadores. Rio de Janeiro: Paz e Terra.

Giudice, V. (1972). O arquivo Necrológio. Rio de Janeiro: O Cruzeiro.

Kupfer, M. C. M. (2000). Freud e a Educação - O mestre do impossível. São Paulo: Ed. Scipione.

Kupfer, M. C. M, Costa, B. H. da, Césaris, D. M. de, Cardoso, F. F, Ornellas, M. de L, Bastos, M. B, Crochik N, \& Palhares, O. (2010) Produção brasileira no campo das articulações entre psicanálise e educação a ser uma passagem privilegiada para o conhecimento histórico, não importa o quão distorcido pela sua própria neurose.

O que se buscou aqui, a partir dos bancos de dados da Capes e das universidades estaduais paulistas foi a construção de um arquivo em forma de história, uma possível história, das muitas que poderiam ser escritas.

partir de 1980. Estilos da clínica, v15(2), 284-305.

Orlandi, E. P. (2001). Análise de discurso: princípios e procedimentos. Campinas: Ed. Pontes.

Patto, M. H. de S. (1992). A família pobre e a escola pública: anotações sobre um desencontro. Psicol. USP, v.3 n.1-2 São Paulo.

Romanowski, J. \& Ens, R. T. (2006). As pesquisas denominadas do tipo "Estado da Arte" em educação. Diálogo Educ. nº19, v.6, 37-50.

Roudinesco, E. (2006). A Análise e o Arquivo. Rio de Janeiro: Zahar.

Teixeira, L.H das N. (2011). Contribuições da criatividade para a dificuldade de ensinar: uma revisão da literatura à luz da psicanálise. Dissertação de mestrado, programa de pós-graduação em Educação Escolar, Universidade Estadual Paulista "Júlio de Mesquita Filho", Araraquara.

Vilela, F. C. B.; Archangelo, A (2013). Fundamentos da escola significativa. São Paulo: Edições Loyola.

\section{Mestrados e doutorados que ilustraram o artigo}

Cortizo, T. L. (2011). O (des)encanto do professor: angústia manifesta na contemporaneidade. Dissertação de Mestrado, Programa de Pesquisa e PósGraduação - Mestrado em Educação e Contemporaneidade, Universidade do Estado da Bahia, Salvador, BA.

Costa, A. M. M. (2011). Laço da laje: jovens produtores de cultura, Dissertação de Mestrado, Programa de Pós Graduação em Educação, cultura e comunicação, 
Universidade do Estado do Rio de Janeiro, Rio de Janeiro, RJ.

Costa, W. S. (2012). A relação professoraluno e seus impasses. Mestrado Profissional, Programa de Pós-Graduação em Psicanálise, Saúde e Sociedade, Universidade Veiga de Almeida, Rio de Janeiro, RJ.

Furtado, L. A. R. (2011). Sua majestade o autista: fascínio, intolerância e exclusão no mundo contemporâneo. Tese de doutorado, Programa de Pós Graduação em Educação, Universidade Federal do Ceará, Fortaleza, CE.

Leite, M. F. (2011). De que serve a Psicanálise à educação escolar, Dissertação de Mestrado, Programa de PósGraduação em Psicanálise, Universidade Estadual de Londrina, Londrina, PR.

Merletti, C. K. I. (2012). Escuta grupal de pais de crianças com problemas de desenvolvimento: uma proposta metodológica baseada na psicanálise, Dissertação de Mestrado, Programa de PósGraduação em Psicologia Escolar e do Desenvolvimento Humano, Universidade de São Paulo, São Paulo, SP.

Moraes, S. P. (2012). Sexualidade e gênero de adolescentes em conflito com a lei, Dissertação de Mestrado, Programa de PósGraduação em Educação e Saúde na Infância e Adolescência, Universidade Federal de São Paulo, São Paulo, SP.

Pereira, J. L. A. (2012). Psicanálise e Educação à distância. Mestrado Profissional, Programa de Pós-Graduação em Psicanálise, Saúde e Sociedade, Universidade Veiga de Almeida, Rio de Janeiro, RJ.

Pinheiro, G. da S. (2011) Psicanálise e Educação: da sustentação do enigma à construção do saber, Dissertação de Mestrado, Programa de Pós Graduação em Educação, Universidade Federal de Juiz de Fora, Juiz de Fora, MG.

Ramos, F. do V. C. (2012). Alunos com transtornos globais de desenvolvimento: da categoria psiquiátrica à particularidade de cada caso no processo de inclusão escolar, Dissertação de Mestrado, Programa de Pós-
Graduação em Educação, Universidade Federal de Minas Gerais, Belo Horizonte, MG.

Silveira, F. T. (2012). Função paterna e seus desdobramentos junto à educação, Dissertação de Mestrado, Programa de PósGraduação em Educação nas Ciências, Universidade Regional do Noroeste do Estado do Rio Grande do Sul, Ijuí, RS.

Zacché, K. S.(2012). Orientadores sociais voluntários no programa liberdade assistida: paradoxos da experiência de Belo Horizonte. Dissertação de Mestrado, Programa de Pós-graduação em Educação: Conhecimento e Inclusão Social, Universidade Federal de Minas Gerais, Belo Horizonte, MG.

Dados sobre as autoras:

- Mariana Yuki Kamada é Coordenadora Pedagógica da E.E. Prof. Dr. Camilo Marques Paula. Graduada em História pela UNICAMP e em Psicologia pela Unesp-Bauru. Mestre em educação pela UNICAMP.

- Lilian Cristine Ribeiro Nascimento é professora Doutora da Faculdade de Educação da Universidade Estadual de Campinas. Graduada em Fonoaudiologia pela Pontifícia Universidade Católica de Campinas. Mestre e doutora em educação pela UNICAMP. 